\title{
A systematic review and meta-analysis on prognosis and survival of hepatocellular carcinoma with lung metastasis after hepatectomy
}

\author{
Xiang $\mathrm{An}^{1 \#}, \mathrm{Fei} \mathrm{Li}{ }^{1 \#}$, Chengjin $\mathrm{Mou}^{2}$, Dexin $\mathrm{Li}^{1}$ \\ ${ }^{1}$ Department of Hepatobiliary Surgery, Eastern Hospital, Sichuan Academy of Medical Sciences \& Sichuan Provincial People's Hospital, Chengdu, \\ China; ${ }^{2}$ Thyroid and Breast Surgery Department, Eastern Hospital, Sichuan Academy of Medical Sciences \& Sichuan Provincial People's Hospital, \\ Chengdu, China \\ Contributions: (I) Conception and design: X An, C Mou; (II) Administrative support: F Li; (III) Provision of study materials or patients: X An, F Li, D \\ Li; (IV) Collection and assembly of data: All authors; (V) Data analysis and interpretation: X An, C Mou, D Li; (VI) Manuscript writing: All authors; \\ (VII) Final approval of manuscript: All authors. \\ "These authors contributed equally to this work. \\ Correspondence to: Chengjin Mou; Dexin Li. Sichuan Academy of Medical Sciences \& Sichuan Provincial People's Hospital, No. 585, Honghe North \\ Road, Chengdu, China. Email: mcj2hh@163.com; lidexin2188@163.com.
}

Background: The most common metastatic site of hepatocellular carcinoma (HCC) is lung metastasis. When the patient has lung metastasis, the development of the disease will become very rapid. In severe cases, it will cause rapid death of the patient. Therefore, the treatment of HCC after lung metastasis has become a hot research topic. This study was designed to investigate the curative effect and prognostic factors of hepatectomy in patients with HCC with lung metastasis (LM) (HCC + LM patients) using meta-analysis.

Methods: RevMan 5.3 software was used to screen literature based on randomized controlled studies on the curative effect and prognostic factors of hepatectomy for HCC + LM published between January 2000 to January 2020 in the PubMed, Web of Science, Spring, and Science Direct databases.

Results: A total of 13 articles were included, comprising 754 patients in the $H$ group and 1,201 patients in the NH group. Meta-analysis results showed that the maximum diameter of liver tumors in the $\mathrm{H}$ group was much larger than that in the $\mathrm{NH}$ group ( $\mathrm{MD}=-0.62 ; 95 \% \mathrm{CI}:-1.20$ to $-0.04 ; \mathrm{Z}=2.09 ; \mathrm{P}=0.04$ ). The survival rate 1,3 , and 5 years after treatment in group $\mathrm{H}$ was higher than that in the $\mathrm{NH}$ group [MantelHaenszel $(\mathrm{MH})=2.91,2.80$, and 4.96; 95\% CI: 2.25-3.76, 2.22-3.52, and 3.74-6.59; Z=8.20, 8.73, and 11.09, respectively; $\mathrm{P}<0.00001$ ], and the mean survival time in group $\mathrm{H}$ was much longer than that in the NH group $(\mathrm{MD}=17.30 ; 95 \% \mathrm{CI}: 11.78-22.83 ; \mathrm{Z}=6.14$; and $\mathrm{P}<0.00001)$.

Discussion: The MDLT is a prognostic indicator for hepatectomy, and hepatectomy can effectively prolong the survival time of HCC + LM patients.

Keywords: Hepatocellular carcinoma (HCC); lung metastasis (LM); hepatectomy; prognosis; meta-analysis

Submitted Jun 17, 2021. Accepted for publication Aug 02, 2021.

doi: 10.21037/apm-21-1784

View this article at: https://dx.doi.org/10.21037/apm-21-1784

\section{Introduction}

Hepatocellular carcinoma (HCC) is a common malignant liver tumor. The incidence of HCC in China ranks fifth among all malignant cancers, and its death toll ranks third among malignant tumors (1). While metastasis recurrence is the main reason for the high mortality of HCC, current research shows recurrent liver lesions can be controlled by radiofrequency ablation (RFA), liver transplantation, 
repeated surgical resection, and radiation therapy. However, there is currently no clear treatment for extrahepatic metastases (2). Several studies have shown that hepatectomy is the most effective and thorough treatment method for liver cancer, but recurrence and metastasis rates after hepatectomy are higher than other methods (3). Liver cancer tumors are more likely to invade the portal vein at an early stage and metastasize to other parts of the liver through it, resulting in recurrence rates within 2 years after resection reaching $70 \%$, and within 3 years of surgery being as high as $81 \%$ (4). Other studies have shown that the multicentric growth of liver tumors causes certain restrictions in the implementation of hepatectomy, and due to the particularity of liver tumor sites, only $25 \%$ of patients can undergo the procedure (5).

Once extrahepatic metastasis occurs in liver cancer, the median survival time is generally about 8.1 months (6). The most common site for extrahepatic metastases is the lung $(38.4 \%)$, followed by bone $(32.6 \%)$ and lymph node metastasis (24.6\%) (7). At present, the treatment of HCC $+\mathrm{LM}$ is controversial. Some researchers believe that HCC + LM patients should be controlled by palliative care and symptomatic supportive treatment (8). However, others have proposed that $\mathrm{HCC}+\mathrm{LM}$ patients can undergo both hepatectomy and distant metastasis resection, and as the deaths of HCC + LM patients are mostly caused by uncontrolled HCC, controlling tumors in the liver is of great significance to the treatment of extrahepatic metastases (9).

In summary, controversy remains as to whether hepatectomy is beneficial to HCC + LM patients. Therefore, a meta-analysis of the relevant treatment methods of hepatectomy in HCC + LM patients was implemented, and the curative effect and prognostic risk factors of $\mathrm{HCC}+\mathrm{LM}$ patients after hepatectomy were discussed and explored to provide reliable references for its clinical treatment.

We present the following article in accordance with the PRISMA reporting checklist (available at https://dx.doi. org/10.21037/apm-21-1784).

\section{Methods}

\section{Inclusion methods}

Patients with primary liver benign tumors and malignant tumors combined with lung metastasis (LM) were selected as the research objects. The types of included studies were retrospective controlled studies and prospective cohort studies. The treatment methods mentioned covered non- hepatectomy treatment in the $\mathrm{NH}$ group which included RFA, radiotherapy, targeted therapy, chemotherapy, radioactive seed implantation, and absolute alcohol injection, while hepatectomy was adopted in the $\mathrm{H}$ group. Observation indicators included basic information of the authors, the number of subjects, age of the subjects, the proportion of patients with preoperative AFP $<20 \mathrm{ng} / \mathrm{mL}$, the number of liver tumors $\geq 2$, MDLT, MDLM, survival rate 1,3 , and 5 years after treatment, and MST after hepatectomy.

\section{Inclusion and exclusion criteria}

Inclusion criteria: SCI papers on clinical trials published between January 2000 to January 2020 providing original data; SCI papers adopting non-hepatectomy and hepatectomy to treat HCC + LM patients, which recorded the patient's age, AFP value, number of liver tumors, MDLT, MDLM, and other parameters before hepatectomy, and those which tracked the survival rates of patients at 1,3 , and 5 years after surgery, and analyzed the MST.

Exclusion criteria: literature that was duplicated; literature reviews; literature published in a non-English language or in which the original data was not available; literature reporting research without an $\mathrm{NH}$ group; animal experiments; literature without index data, or which referred to patients who had not undergone surgery for various reasons.

\section{Literature search strategy}

The keywords "HCC", "pulmonary", "metastasis", "hepatectomy", and "meta-analysis" were searched online in PubMed (2000-1/2020), Nature (2000-1/2020), Web of Science (2000-1/2020), Springer (2000-1/2020), and Science Direct (2000-1/2020). In addition, the keywords were linked with "or" and "and". Publicly published clinical studies on the treatment of HCC patients with lung metastases using hepatectomy during the current search period were searched again, and all keywords were freely combined. After multiple searches, the search engine was used to track the documents.

\section{Literature screening and data extraction}

The selection of relevant documents and extraction of research indicators were independently performed by two investigators, while a third investigator was consulted when 
was consensus could not be reached. Finally, the Cochrane Evaluation Manual 4.2.6 was employed to evaluate included literature. Literature was divided into three grades; low deviation, moderate deviation, and high deviation. The evaluation criteria included: whether the surgical method was correct and clear; whether the research results were clear; and whether the intention-to-treat analysis method was applied to the results. The literature was initially screened by reading the titles, and the original author was contacted where possible to resolve any uncertainty. The abstract and full text were then read to determine eligibility. Information on all available variables from selected studies was then extracted and entered into a Microsoft Excel database. This included: (I) basic information: article title, first author, year of publication, journal published, research type, and start and end time of the research; (II) research objects: number of samples included in the study and age and gender ratio of the research objects; (III) evaluation methods: preoperative index detection and evaluation, and postoperative survival tracking and statistics; (IV) observation indicators: age, proportion of patients with AFP $<20 \mathrm{ng} / \mathrm{mL}$, number of liver tumors $\geq 2$, MDLT, MDLM, SR 1,3 , and 5 years after treatment, and MST.

\section{Statistical analysis}

All data were analyzed with STATA 12.0 software (Stata Corporation, College Station, Texas, USA). For the heterogeneity of the results, Cochran's chi-square test was employed, the test level $\alpha=0.1$, and $\mathrm{I}^{2}$ was to quantitatively analyze the size of the heterogeneity. The appropriate merging method was selected according to the results of the heterogeneity test. If $\mathrm{P}>0.1$ and $\mathrm{I}^{2} \leq 50 \%$, the heterogeneity of the included studies was small, and the fixed effects model (FEM) was adopted for merging. If $\mathrm{P} \leq 0.1$ and $\mathrm{I}^{2}>50 \%$, the included studies were heterogeneous, and further analysis to determine and minimize the source of heterogeneity was conducted. After the influence of heterogeneity was excluded, the random effects model (REM) was utilized for meta-analysis.

The enumeration data was represented by relative risk (RR), and the measurement data was represented by mean deviation (MD) and standard deviation (SD). Each effect size was given its point estimate and $95 \%$ CI, and if necessary, the MD and SD could be estimated based on the available median and CI or range. The sensitivity was analyzed by excluding studies with the lowest quality scores. Meta-analysis was performed according to the time sequence of literature publication to evaluate the stability of the effect size, and the inspection level satisfied $=0.05$.

\section{Results}

\section{Document screening process and search results}

The initial search retrieved 338 English articles. The distribution of articles saw 156, 85, 37, 19, and 28 in the PubMed, Web of Science, Spring, Nature, and Science Direct database, respectively, while 13 articles were retrieved from the referenced literature and reviews. After repetitive articles were screened using Endnote X8 software, 162 were obtained, then following the exclusion of reviews, conference essays, case analysis, and risk factor assessment based on the literature titles, article abstracts, and research contents, 25 articles remained. After further intensive reading of the articles, 13 with no original data and uncontrolled studies were excluded, and 12 were finally included for analysis. Specific information regarding each article is shown in Table 1 .

\section{Age of patients}

A total of nine articles analyzed the age of subjects, and meta-analysis results show there was no remarkable difference in the ages of the two groups of patients (heterogeneity $\mathrm{I}^{2}=29 \%$, and $\mathrm{P}=0.18$ ) (Figure 1 ). Further analysis using an REM showed that there also no statistical difference in age between the two groups ( $M D=-0.70,95 \%$ CI: -2.32 to $0.91 ; \mathrm{Z}=0.851$, and $\mathrm{P}=0.39$ ).

\section{Alpha fetoprotein value}

A total of eight articles tested AFP in HCC + LM patients before surgery, and statistically analyzed the proportion of patients with AFP $<20 \mathrm{ng} / \mathrm{mL}$. The results show there was no obvious heterogeneity in the proportion of patients with AFP $<20 \mathrm{ng} / \mathrm{mL}$ before hepatectomy in group $\mathrm{H}$ and $\mathrm{NH}$ $\left(\mathrm{I}^{2}=0 \%\right.$, and $\left.\mathrm{P}=0.56\right)$ (Figure 2). Further analysis using REM showed that the proportion of two groups of patients with AFP $<20 \mathrm{ng} / \mathrm{mL}$ was not statistically different $(\mathrm{RD}=-0.02$, 95\% CI: -0.06 to $0.021 ; \mathrm{Z}=0.82, \mathrm{P}=0.41$ ).

\section{Number of tumors}

The number of liver tumors in HCC + LM patients was reported in eight articles, and the proportion of patients 
Table 1 Basic information of the included literature

\begin{tabular}{|c|c|c|c|c|c|}
\hline Included study & State & Study design & $\begin{array}{l}\text { Total number } \\
\text { of patients }\end{array}$ & $\begin{array}{l}\text { Number of patients } \\
\text { in group } \mathrm{H}\end{array}$ & $\begin{array}{l}\text { Number of patients } \\
\text { in group } \mathrm{NH}\end{array}$ \\
\hline Tomimaru [2006] (10) & Japan & Retrospective controlled study & 14 & 8 & 6 \\
\hline Zhang [2008] (11) & China & Retrospective controlled study & 105 & 41 & 64 \\
\hline $\mathrm{Hu}$ [2017] (12) & China & Retrospective controlled study & 97 & 71 & 26 \\
\hline Hu [2018] (14) & China & Retrospective controlled study & 81 & 9 & 72 \\
\hline Li [2014] (15) & China & Prospective controlled study & 828 & 218 & 610 \\
\hline Zhao [2017] (16) & China & Retrospective controlled study & 118 & 54 & 64 \\
\hline Vlad [2014] (17) & France & Retrospective controlled study & 35 & 16 & 19 \\
\hline Kow [2015] (21) & Korea & Retrospective controlled study & 41 & 30 & 11 \\
\hline
\end{tabular}

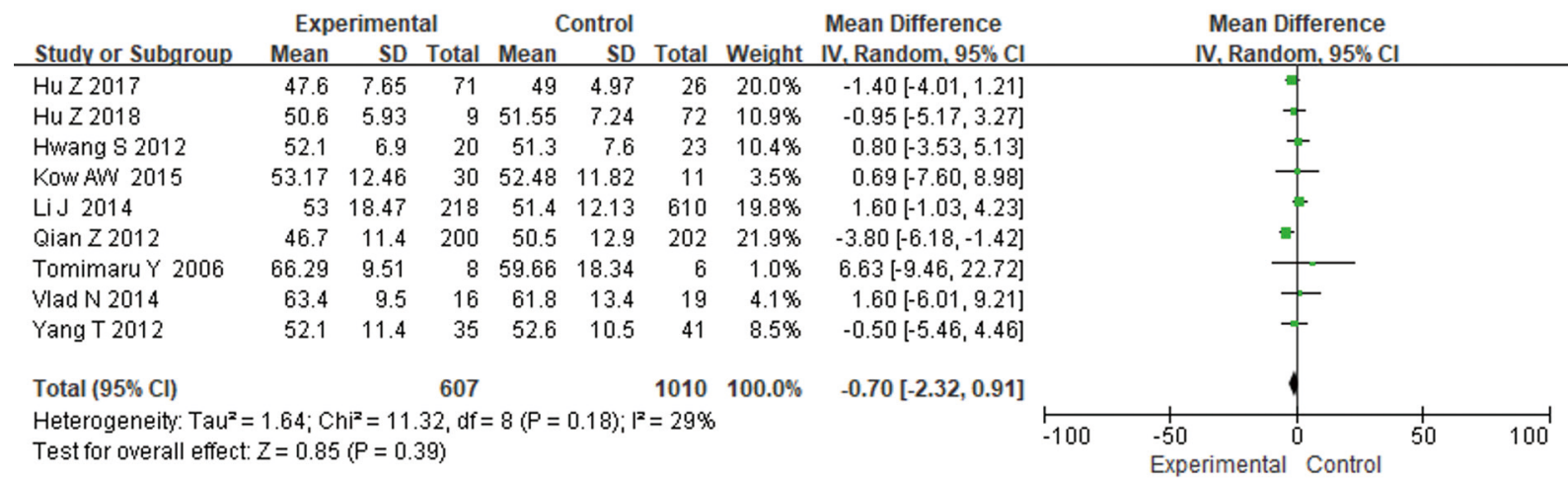

Figure 1 Age comparison between patients in the two groups.

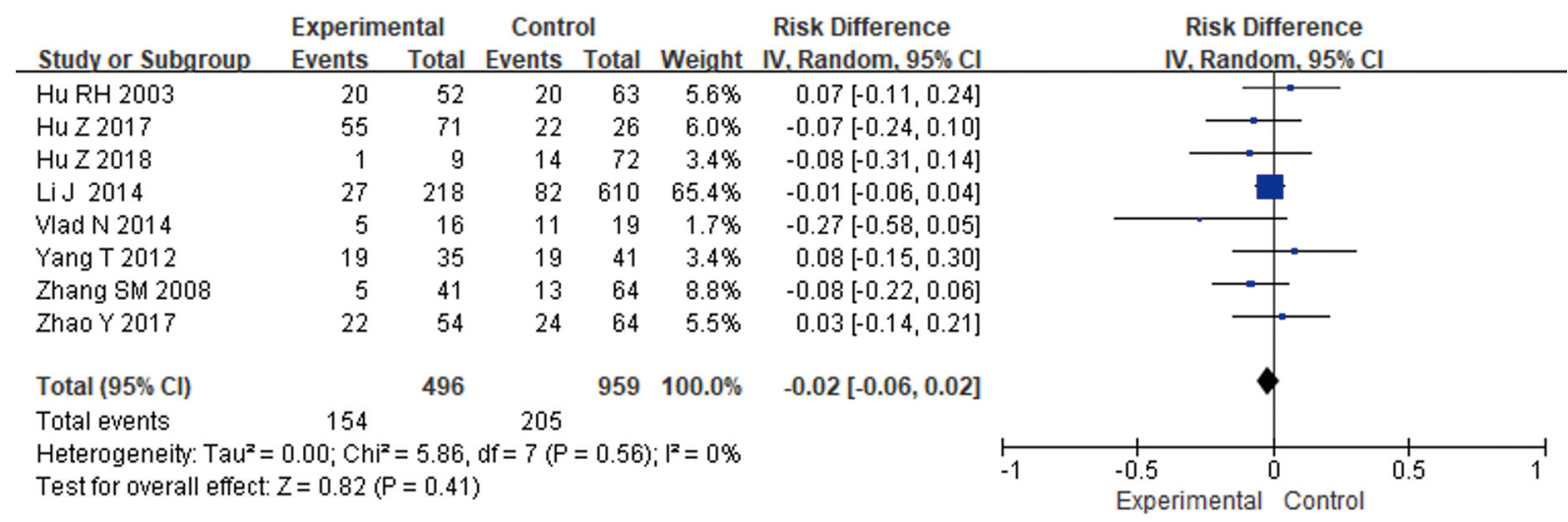

Figure 2 Comparison AFP values between the two groups before surgery. AFP, Alpha fetoprotein. 


\begin{tabular}{|c|c|c|c|c|c|c|c|c|c|c|c|}
\hline Study or Subgroup & \multicolumn{2}{|c|}{ Experimental } & \multicolumn{2}{|c|}{ Control } & \multicolumn{2}{|c|}{$\begin{array}{c}\text { Risk Difference } \\
\text { Weight } \\
\text { IV. Random, } 95 \% \mathrm{Cl} \\
\end{array}$} & & \multicolumn{2}{|c|}{$\begin{array}{c}\text { Risk Difference } \\
\text { IV. Random, } 95 \% \mathrm{Cl}\end{array}$} & & \\
\hline Hu RH 2003 & 7 & 52 & 13 & 63 & $13.4 \%$ & $-0.07[-0.21,0.06]$ & & $\rightarrow$ & & & \\
\hline Hu Z 2017 & 30 & 71 & 9 & 26 & $5.3 \%$ & $0.08[-0.14,0.29]$ & & & & & \\
\hline Hu Z 2018 & 2 & 9 & 16 & 72 & $3.0 \%$ & $0.00[-0.29,0.29]$ & & & & & \\
\hline Hwang $S 2012$ & 12 & 20 & 12 & 23 & $2.8 \%$ & $0.08[-0.22,0.37]$ & & & & & \\
\hline Qian Z 2012 & 19 & 200 & 32 & 202 & $59.4 \%$ & $-0.06[-0.13,0.00]$ & & -1 & & & \\
\hline Vlad N 2014 & 5 & 16 & 5 & 19 & $2.7 \%$ & $0.05[-0.25,0.35]$ & & & & & \\
\hline Yang T 2012 & 21 & 35 & 24 & 41 & $5.1 \%$ & $0.01[-0.21,0.24]$ & & & & & \\
\hline Zhao Y 2017 & 20 & 54 & 21 & 64 & $8.3 \%$ & $0.04[-0.13,0.21]$ & & & & & \\
\hline Total $(95 \% \mathrm{Cl})$ & & 457 & & 510 & $100.0 \%$ & $-0.04[-0.09,0.01]$ & & & & & \\
\hline Total events & 116 & & 132 & & & & & & & & \\
\hline $\begin{array}{l}\text { Heterogeneity: Tauz } \\
\text { Test for overall effec }\end{array}$ & $\begin{array}{l}0.00 ; \mathrm{Chi}^{-} \\
\mathrm{Z}=1.39\end{array}$ & $\begin{array}{l}=3.92, \\
=0.16)\end{array}$ & $d f=?(P$ & $=0.79)$ & $i^{2}=0 \%$ & & -1 & $\begin{array}{l}-0.5 \\
\text { Experimental }\end{array}$ & Control & 0.5 & 1 \\
\hline
\end{tabular}

Figure 3 Proportion of patients with number of liver tumors $\geq 2$ in patients of the two groups.

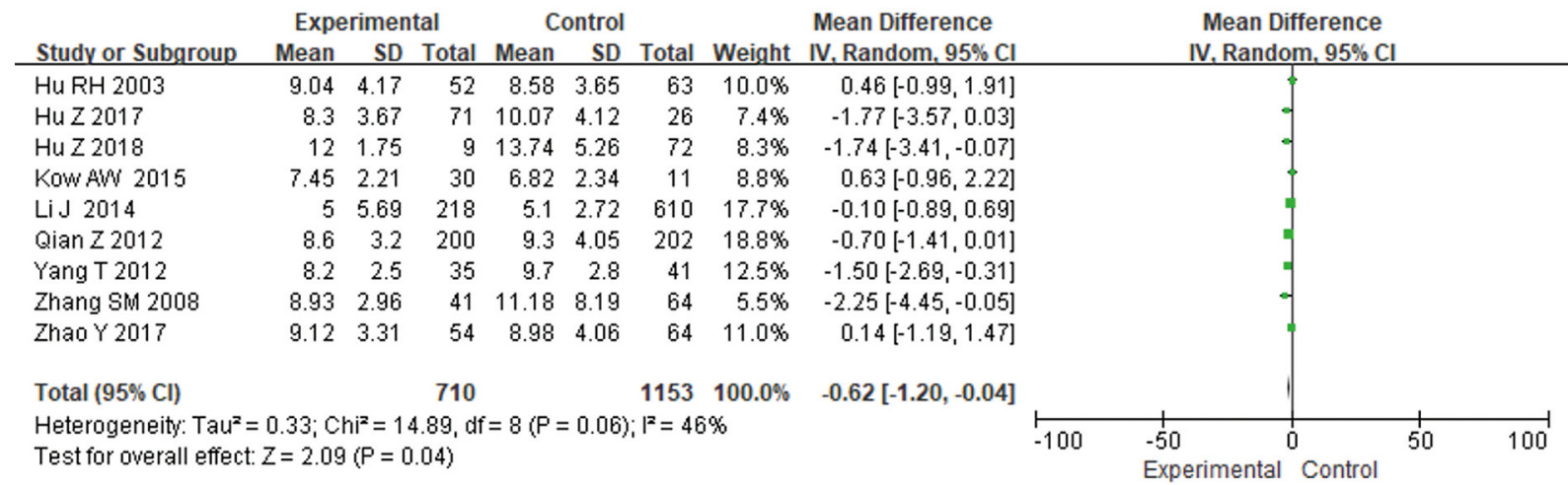

Figure 4 Maximal diameter of liver tumors of patients in the two groups.

with $\geq 2$ tumors was counted in the two groups. Figure 3 shows that the proportion of patients with $\geq 2$ tumors in group $\mathrm{H}$ and group $\mathrm{NH}$ was visibly heterogeneous $\left(\mathrm{I}^{2}=0 \%\right.$, and $\mathrm{P}=0.79)$, and analysis using REM revealed that the proportion of the two groups of patients with liver tumors $\geq 2$ did not differ statistically ( $R D=-0.04,95 \%$ CI: -0.09 to $0.01 ; \mathrm{Z}=1.39$, and $\mathrm{P}=0.16$ ).

\section{Maximum diameter of liver tumor}

A total of nine articles analyzed the MDLT of HCC + LM patients, and the results are shown in Figure 4. While it can be seen that the MDLT in the two groups had no obvious heterogeneity $\left(\mathrm{I}^{2}=46 \%, \mathrm{P}=0.06\right)$, analysis using $\mathrm{REM}$ disclosed that MDLT between the two groups showed great difference $(\mathrm{MD}=-0.62,95 \% \mathrm{CI}:-1.20$ to $-0.04 ; Z=2.09$, $\mathrm{P}=0.04)$.

\section{Maximal diameter of $L M$}

The MDLM of HCC + LM patients was determined in five articles and the results are given in Figure 5. The heterogeneity between group $\mathrm{H}$ and group $\mathrm{NH}$ was obvious in MDLM ( $\left.\mathrm{I}^{2}=61 \%, \mathrm{P}=0.04\right)$, and the analysis based on REM showed no statistical difference in MDLM between the two groups $(\mathrm{MD}=-0.09,95 \% \mathrm{CI}:-0.30$ to 0.13 ; $\mathrm{Z}=0.80, \mathrm{P}=0.42$ ).

\section{Survival rate 1 year after bepatectomy}

The SS 1 year after treatment was tracked in 11 articles and the results are shown in Figure 6. There was no notable heterogeneity in SS 1 year after treatment for different methods $\left(\mathrm{I}^{2}=0 \%, \mathrm{P}=0.63\right)$, and further analysis with FEM suggested there was no obvious difference in SS between 


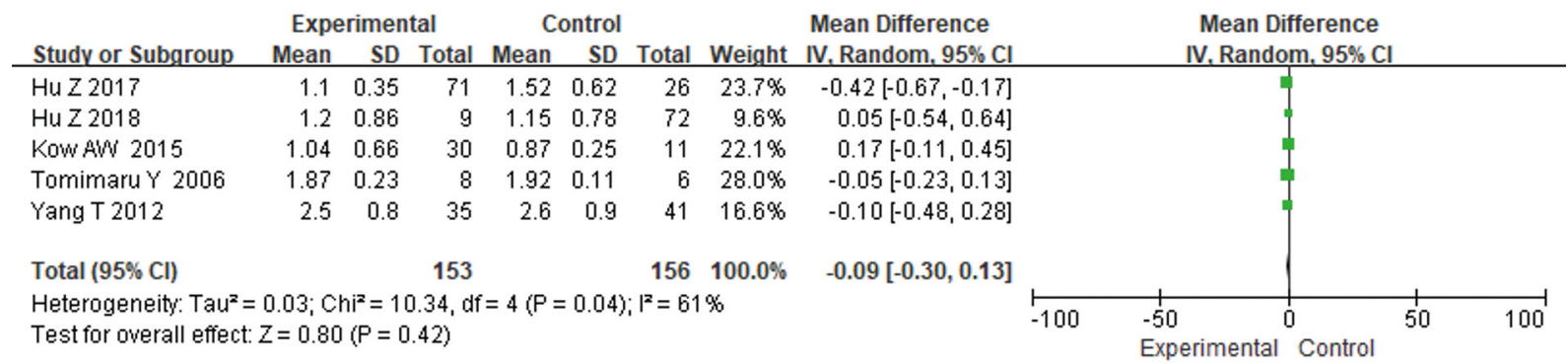

Figure 5 Comparison on maximal diameter of lung metastasis in the two groups of patients.

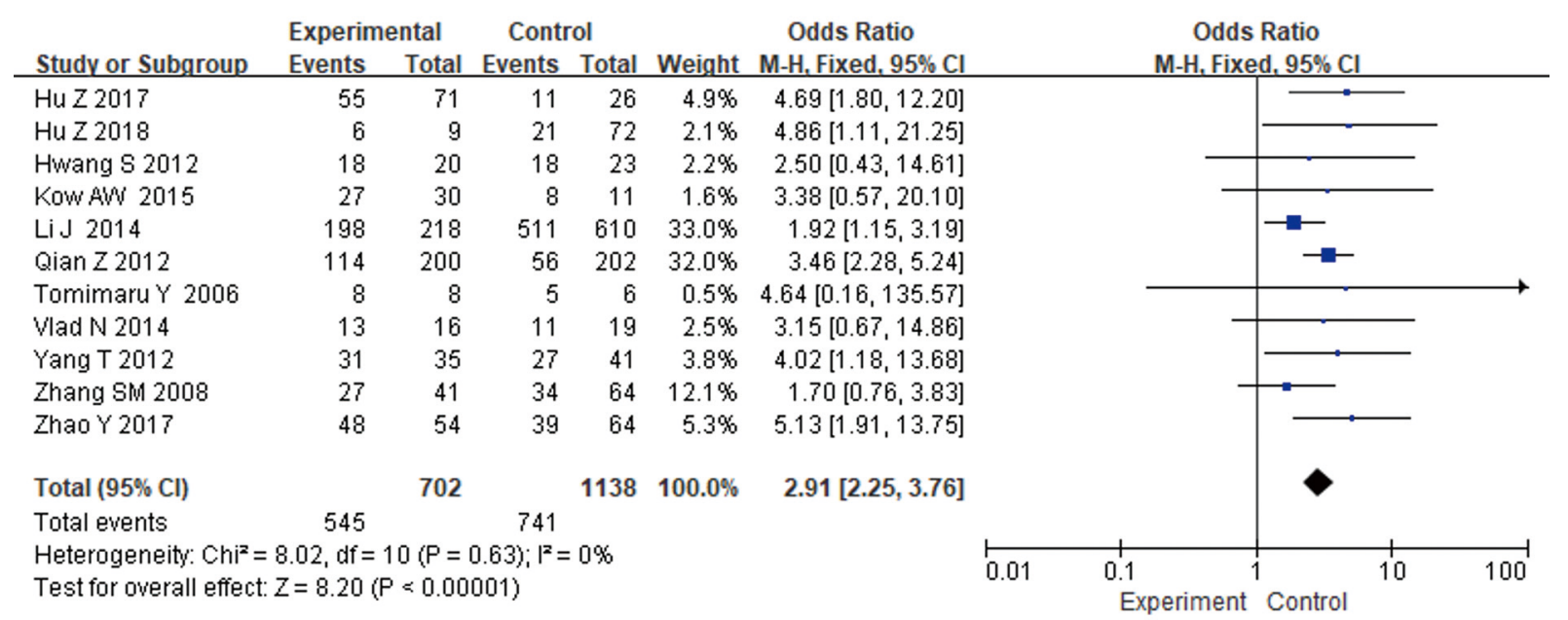

Figure 6 Survival rate 1 year after the surgery for the two groups of patients.

the two groups $(\mathrm{MH}=2.91,95 \% \mathrm{CI}: 2.25-3.76 ; \mathrm{Z}=8.20$, $\mathrm{P}<0.00001)$.

\section{Survival rate 3 years after hepatectomy}

The SS 3 years after treatment was tracked in 11 articles, and the results are shown in Figure 7. There was a notable heterogeneity in SS 3 years after the surgery for different methods $\left(\mathrm{I}^{2}=68 \%, \mathrm{P}=0.0005\right)$, and further analysis with FEM showed there was no obvious statistical difference between the two groups $(\mathrm{MH}=2.80,95 \% \mathrm{CI}: 2.22-3.52$; $\mathrm{Z}=8.73, \mathrm{P}<0.00001)$.

\section{Survival rate 5 years after hepatectomy}

The SS 5 years after treatment was also tracked in 11 articles, and the results are shown in Figure 8. This shows there was no visible heterogeneity in SS 5 years after the surgery for different methods $\left(\mathrm{I}^{2}=10 \%, \mathrm{P}=0.35\right)$, while further analysis using FEM indicated that there was no statistical difference between the two groups $(\mathrm{MH}=4.96$, 95\% CI: 3.74-6.59; $\mathrm{Z}=11.09, \mathrm{P}<0.00001)$.

\section{Mean survival time}

The MST was tracked and counted in different groups of patients and the results are illustrated in Figure 9. There was a remarkable heterogeneity in MST after hepatectomy for different treatment methods $\left(\mathrm{I}^{2}=98 \%, \mathrm{P}<0.00001\right)$, and the REM disclosed a dramatic statistical difference in MST after surgery between the two groups $(\mathrm{MD}=17.30,95 \% \mathrm{CI}$ : 11.78-22.83; $\mathrm{Z}=6.14, \mathrm{P}<0.00001)$.

\section{Discussion}

Liver cancer is one of the common malignant tumors. Primary liver cancer mainly includes HCC, cholangiocarcinoma, mixed HCC, and cholangiocarcinoma (22), among which, 


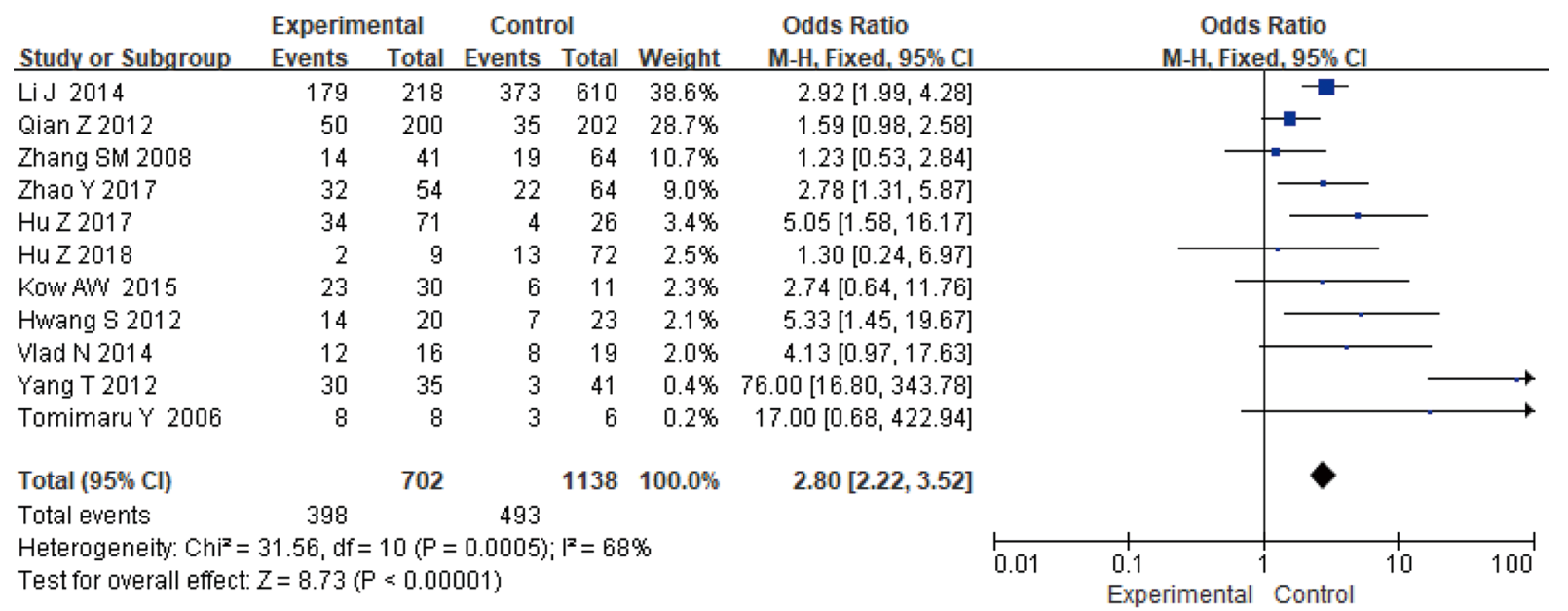

Figure 7 Survival rate 3 years after the surgery for the two groups of patients.

\begin{tabular}{|c|c|c|c|c|c|c|c|c|c|c|c|}
\hline Study or Subgroup & \multicolumn{2}{|c|}{ Experimental } & \multicolumn{2}{|c|}{ Control } & Weight & $\begin{array}{c}\text { Odds Ratio } \\
\text { M-H, Fixed, } 95 \% \mathrm{Cl}\end{array}$ & \multicolumn{5}{|c|}{$\begin{array}{c}\text { Odds Ratio } \\
\text { M-H, Fixed, } 95 \% \mathrm{Cl}\end{array}$} \\
\hline Hu Z 2017 & 21 & 71 & 2 & 26 & $4.7 \%$ & $5.04[1.09,23.27]$ & & & & & \\
\hline Hu Z 2018 & 0 & 72 & 0 & 9 & & Not estimable & & & & & \\
\hline Hwang S 2012 & 9 & 20 & 3 & 23 & $3.5 \%$ & $5.45[1.22,24.43]$ & & & & & \\
\hline Kow AW 2015 & 17 & 30 & 4 & 11 & $5.8 \%$ & $2.29[0.55,9.52]$ & & & & & \\
\hline Li.J 2014 & 84 & 218 & 52 & 610 & $38.3 \%$ & $6.73[4.54,9.97]$ & & & & - - & \\
\hline Qian Z 2012 & 38 & 200 & 8 & 202 & $14.7 \%$ & $5.69[2.58,12.54]$ & & & & & \\
\hline Tomimaru Y 2006 & 5 & 8 & 1 & 6 & $1.0 \%$ & $8.33[0.63,110.02]$ & & & & & \\
\hline Vlad N 2014 & 5 & 16 & 2 & 19 & $2.9 \%$ & $3.86[0.63,23.53]$ & & & & & \\
\hline Yang T 2012 & 11 & 35 & 3 & 41 & $4.3 \%$ & $5.81[1.47,22.96]$ & & & & & \\
\hline Zhang SM 2008 & 6 & 41 & 7 & 64 & $10.6 \%$ & $1.40[0.43,4.49]$ & & & & & \\
\hline Zhao Y 2017 & 20 & 54 & 11 & 64 & $14.4 \%$ & $2.83[1.21,6.65]$ & & & & & \\
\hline Total $(95 \% \mathrm{Cl})$ & & 765 & & 1075 & $100.0 \%$ & $4.96[3.74,6.59]$ & & & & & \\
\hline Total events & 216 & & 93 & & & & & & & & \\
\hline $\begin{array}{l}\text { Heterogeneity: } \mathrm{Chi}^{2}= \\
\text { Test for overall effect }\end{array}$ & $\begin{array}{l}10.01, d f= \\
Z=11.09\end{array}$ & $\begin{array}{l}9(P=0 \\
P<0.0\end{array}$ & $\begin{array}{l}0.35) ;\left.\right|^{2}= \\
0001)\end{array}$ & $10 \%$ & & & 0.01 & $\begin{array}{l}0.1 \\
\text { s [ex }\end{array}$ & ${ }_{\text {imental] }}^{1}$ & $\begin{array}{c}10 \\
\text { Favours [control] }\end{array}$ & 100 \\
\hline
\end{tabular}

Figure 8 Survival rate 5 years after the surgery for the two groups of patients.

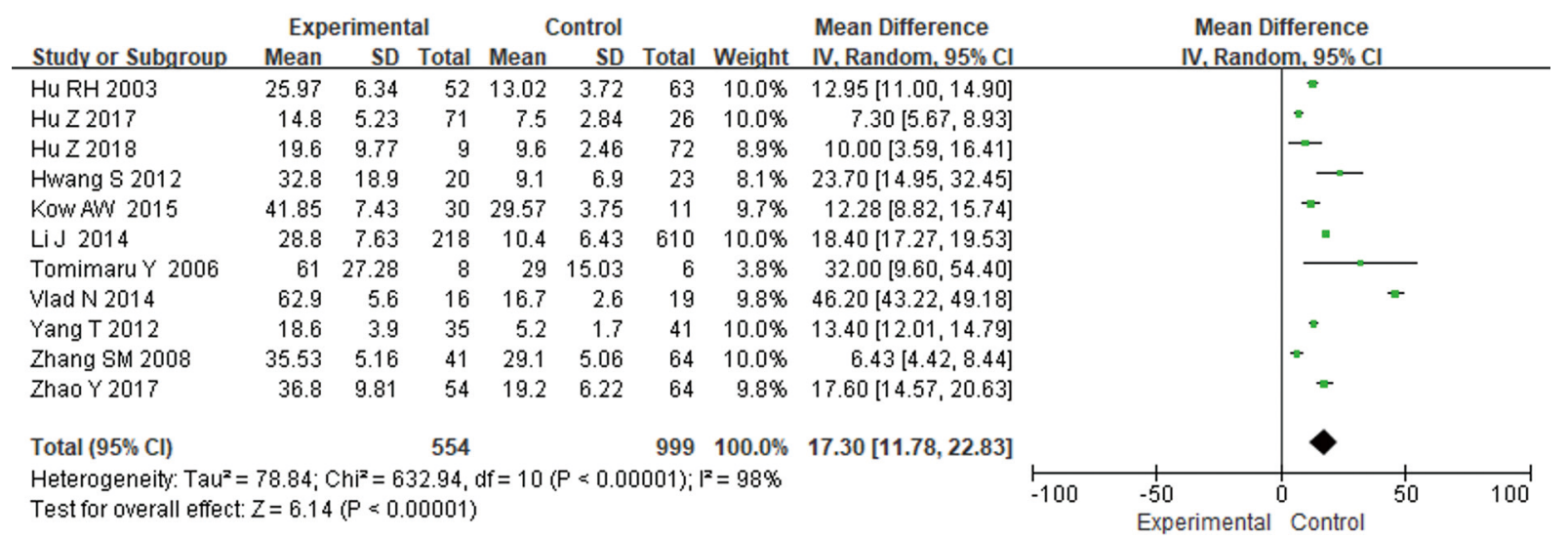

Figure 9 Comparison on mean survival time for the two groups of patients. 
HCC accounts for the highest proportion, reaching $90 \%$ (23). With the progress and development of modern medical technology and the popularization of evidencebased medicine, the National Comprehensive Cancer Network (NCCN) provided clear supplements and explanations for the diagnosis and treatment of liver cancer in 2015 (24). However, despite this and recent improvements in morbidity and mortality, the current prognosis of liver cancer patients is still poor.

The lung is the most common site of extrahepatic metastasis in patients with liver cancer, and its metastasis rate has reached $43.4 \%$ (25). This is because of its lower circulation pressure than other body regions, which allows cancer cells to easily accumulate, increasing the probability of metastasis (26). Patients with LM are often in the advanced stage of liver cancer, which seriously affects the prognosis (27). The current treatment of liver cancer with metastases remains controversial. Currently, surgical resection, chemotherapy, radiotherapy, RFA, targeted therapy, and absolute alcohol injection are used to treat HCC lesions with LM (28). While chemotherapy for HCC combined with distant metastasis of other organs is a better treatment method, most patients experience intolerance during chemotherapy, and their SS decreases significantly (29). Surgical resection is also an effective means to treat patients with HCC metastasis, but even it has a high recurrence rate of around $70 \%$ within 5 years of surgery (30). AFP is a globulin produced by the liver and yolk sac. The abnormal differentiation of cancer cells in patients with liver cancer results in a significantly higher AFP content than normal humans (31). Moreover, the content of AFP in serum has a significant correlation with the number of cancer cells and degree of differentiation of liver cancer. Serum AFP content is directly proportional to tumor diameter, and as its content increases, recurrence and metastasis are more likely to occur (32). Therefore, the content of AFP in serum has important value for the diagnosis and treatment of liver cancer and the prediction of recurrence.

This meta-analysis included 12 clinical studies on the treatment of HCC + LM patients by hepatectomy, and the curative effect, prognosis, and SS of HCC + LM patients receiving and not receiving hepatectomy were compared. The results showed MDLT was much larger in the $\mathrm{H}$ group, and the SS 1, 3, and 5 years after surgery of the $\mathrm{H}$ group were much higher than those of the $\mathrm{NH}$ group. The MST in the $\mathrm{H}$ group was also obviously longer in contrast to the NH group. The results also showed that MDLT could be used as a prognostic indicator of hepatectomy, and hepatectomy could effectively extend the SS of patients after surgery and extend the survival time of HCC + LM patients.

\section{Conclusions}

This study used a meta-analysis to find and explore 12 articles evaluating the curative effect, prognosis, and SS of HCC + LM patients after hepatectomy. The results showed that in patients receiving hepatectomy, MDLT was significantly larger, the 1 year, 3 years, and 5 years SS after surgery were considerably longer, and the MST was greatly extended, in comparison to a non-hepatectomy group. This shows that MDLT could be used as a prognostic indicator of hepatectomy, and that hepatectomy could effectively prolong the SS and extend the survival time of HCC + LM patients after surgery. Although this study did not analyze the postoperative complications and recurrence rate, the results still provide a reliable theoretical basis for the prognosis and survival of $\mathrm{HCC}+\mathrm{LM}$ patients after hepatectomy.

\section{Acknowledgments}

Funding: None.

\section{Footnote}

Reporting Checklist: The authors have completed the PRISMA reporting checklist. Available at https://dx.doi. org/10.21037/apm-21-1784

Conflicts of Interest: All authors have completed the ICMJE uniform disclosure form (available at https://dx.doi. org/10.21037/apm-21-1784). The authors have no conflicts of interest to declare.

Ethical Statement: The authors are accountable for all aspects of the work in ensuring that questions related to the accuracy or integrity of any part of the work are appropriately investigated and resolved.

Open Access Statement: This is an Open Access article distributed in accordance with the Creative Commons Attribution-NonCommercial-NoDerivs 4.0 International License (CC BY-NC-ND 4.0), which permits the noncommercial replication and distribution of the article with 
the strict proviso that no changes or edits are made and the original work is properly cited (including links to both the formal publication through the relevant DOI and the license). See: https://creativecommons.org/licenses/by-nc-nd/4.0/.

\section{References}

1. Hartke J, Johnson M, Ghabril M. The diagnosis and treatment of hepatocellular carcinoma. Semin Diagn Pathol 2017;34:153-9.

2. Clark T, Maximin S, Meier J, et al. Hepatocellular Carcinoma: Review of Epidemiology, Screening, Imaging Diagnosis, Response Assessment, and Treatment. Curr Probl Diagn Radiol 2015;44:479-86.

3. Wallace MC, Preen D, Jeffrey GP, et al. The evolving epidemiology of hepatocellular carcinoma: a global perspective. Expert Rev Gastroenterol Hepatol 2015;9:765-79.

4. Degasperi E, Colombo M. Distinctive features of hepatocellular carcinoma in non-alcoholic fatty liver disease. Lancet Gastroenterol Hepatol 2016;1:156-64.

5. Nishida N, Kudo M. Oncogenic Signal and Tumor Microenvironment in Hepatocellular Carcinoma. Oncology 2017;93 Suppl 1:160-4.

6. Zhang X, Li J, Shen F, et al. Significance of presence of microvascular invasion in specimens obtained after surgical treatment of hepatocellular carcinoma. J Gastroenterol Hepatol 2018;33:347-54.

7. Guo X, Xu Y, Wang X, et al. Advanced Hepatocellular Carcinoma with Bone Metastases: Prevalence, Associated Factors, and Survival Estimation. Med Sci Monit 2019;25:1105-12.

8. Nosaka T, Baba T, Tanabe Y, et al. Alveolar Macrophages Drive Hepatocellular Carcinoma Lung Metastasis by Generating Leukotriene B4. J Immunol 2018;200:1839-52.

9. Mao K, Wang J. Present treatment situation of hepatocellular carcinoma with extrahepatic metastasis. Zhonghua Wai Ke Za Zhi 2019;57:466-70.

10. Tomimaru Y, Sasaki Y, Yamada T, et al. The significance of surgical resection for pulmonary metastasis from hepatocellular carcinoma. Am J Surg 2006;192:46-51.

11. Zhang SM, Zeng ZC, Tang ZY, et al. Prognostic analysis of pulmonary metastases from hepatocellular carcinoma. Hepatol Int 2008;2:237-43.

12. Hu Z, Li W, Huang $P$, et al. Therapeutic significance and indications of pulmonary metastasectomy for hepatocellular carcinoma following liver resection. Int J Surg 2017;48:23-31.
13. Hwang S, Kim YH, Kim DK, et al. Resection of pulmonary metastases from hepatocellular carcinoma following liver transplantation. World J Surg 2012;36:1592-602.

14. Hu Z, Huang P, Zhou Z, et al. Aggressive intrahepatic therapies for synchronous hepatocellular carcinoma with pulmonary metastasis. Clin Transl Oncol 2018;20:729-39.

15. Li J, Liu Y, Yan Z, et al. A nomogram predicting pulmonary metastasis of hepatocellular carcinoma following partial hepatectomy. Br J Cancer 2014;110:1110-7.

16. Zhao Y, Leng S, Li D, et al. Pulmonary function impairment predicted poor prognosis of patients with hepatocellular carcinoma after hepatectomy. Oncotarget 2017;8:75326-35.

17. Vlad N, Gouillat C, Moldovanu R, et al. Radiofrequency ablation device assisted liver resection for hepatocellular carcinoma. Chirurgia (Bucur) 2014;109:500-6.

18. Yang T, Lu JH, Lin C, et al. Concomitant lung metastasis in patients with advanced hepatocellular carcinoma. World J Gastroenterol 2012;18:2533-9.

19. Hu RH, Lee PH, Chang YC, et al. Treatment of centrally located hepatocellular carcinoma with central hepatectomy. Surgery 2003;133:251-6.

20. Zhu Q, Yan J, Zhang X, et al. Long-term survival for spontaneous rupture of hepatocellular carcinoma treated with hepatectomy. Journal of Medical Colleges of PLA 2012;27:161-82.

21. Kow AW, Kwon CH, Song S, et al. Clinicopathological factors and long-term outcome comparing between lung and peritoneal metastasectomy after hepatectomy for hepatocellular carcinoma in a tertiary institution. Surgery 2015;157:645-53.

22. Lin CC, Yang HM. Fibrolamellar Carcinoma: A Concise Review. Arch Pathol Lab Med 2018;142:1141-5.

23. Kassahun WT. Contemporary management of fibrolamellar hepatocellular carcinoma: diagnosis, treatment, outcome, prognostic factors, and recent developments. World J Surg Oncol 2016;14:151.

24. Ueno M, Takabatake H, Kayahara T, et al. Mucinproducing hepatocellular carcinoma without morphological features of biliary differentiation: A case report. Medicine (Baltimore) 2018;97:e12159.

25. Chen D, Li Z, Song Q, et al. Clinicopathological features and differential diagnosis of hepatocellular carcinoma in extrahepatic metastases. Medicine (Baltimore) 2018;97:e13356.

26. Han KN, Kim YT, Yoon JH, et al. Role of surgical resection for pulmonary metastasis of hepatocellular 
carcinoma. Lung Cancer 2010;70:295-300.

27. Sun YF, Guo W, Xu Y, et al. Circulating Tumor Cells from Different Vascular Sites Exhibit Spatial Heterogeneity in Epithelial and Mesenchymal Composition and Distinct Clinical Significance in Hepatocellular Carcinoma. Clin Cancer Res 2018;24:547-59.

28. He C, Zhou Z, Xiao Z, et al. Treatment strategy for huge hepatocellular carcinoma with intrahepatic metastasis and macrovascular invasion: a case report and literature review. J Cancer Res Ther 2018;14:S1233-6.

29. Yang X, Xie J, Liu X, et al. Autophagy induction by xanthoangelol exhibits anti-metastatic activities in hepatocellular carcinoma. Cell Biochem Funct 2019;37:128-38.

30. Mizejewski GJ. Review of the Third Domain Receptor
Binding Fragment of Alphafetoprotein (AFP): Plausible Binding of AFP to Lysophospholipid Receptor Targets. Curr Drug Targets 2017;18:874-86.

31. Opriță R, Diaconescu IB, Lupu G, et al. Hepatocellular carcinoma among cirrhotics--utility of screening and surveillance programs--review article. J Med Life 2014;7:477-80.

32. Liu Y, Wang YR, Wang L, et al. Significance of detecting circulating hepatocellular carcinoma cells in peripheral blood of hepatocellular carcinoma patients by nested reverse transcription-polymerase chain reaction and its clinical value: a retrospective study. Tumori 2014;100:536-40.

(English Language Editor: B. Draper)
Cite this article as: An X, Li F, Mou C, Li D. A systematic review and meta-analysis on prognosis and survival of hepatocellular carcinoma with lung metastasis after hepatectomy. Ann Palliat Med 2021;10(8):9039-9048. doi: 10.21037/apm-211784 